\title{
Detection of Urban and Environmental Changes via Remote Sensing
}

\author{
Karim Ennouri ${ }^{1}$ (D) Slim Smaoui ${ }^{2} \cdot$ Mohamed Ali Triki $^{1}$
}

Received: 12 January 2021 / Accepted: 16 March 2021 / Published online: 21 March 2021

(C) The Author(s), under exclusive licence to Springer Nature Switzerland AG 2021

\begin{abstract}
Rapid climate and environmental change at limited, regional, and general scales have been a major concern for researchers in a number of fields, such as topography, economy, environment, and sustainable development. Changes in land cover and land use have taken into account due to potential impacts on soil depletion, amplified run-off, water balance, and climate change. A detailed understanding of the characteristics of land exploitation and land structure is indispensable for the study of their influences on life and nature. In addition, urban extension is a major form of land extraction and land transformation, as it relates to the rise in population and the availability of financial services. Remote sensing records have been shown to be important for reporting and perceiving urban development and transition, and for providing critical information for future growth. Transformation and shift identification are the tools used to recognise distinctions in a land cover by tracking them at various times. In addition, various change identification and detection approaches are routinely tested with the goal of providing the greatest change detection deductions for a particular appliance. This review would aim to establish a practical plan that combines remote sensing techniques, on the one hand, and modelling approaches, on the other, to track land use, to cover changes, and to predict future trends.
\end{abstract}

Keywords Remote sensing · Land cover · Urban extension · Change

\section{Introduction}

Changes in the surface of the globe have significant consequences for the global radiation balance and energy flows, contributing to changes in biogeochemical cycles and changes in

Karim Ennouri

1karimennouri1@gmail.com

1 Laboratory of Amelioration and Protection of Olive Genetic Resources, Olive Tree Institute, University of Sfax, Sfax, Tunisia

2 Laboratory of Microorganisms and Biomolecules of the Center of Biotechnology of Sfax-Tunisia, Road of Sidi Mansour, Km 6 B.P. 1117, 3018 Sfax, Tunisia 
hydrological cycles, and affecting ecological balances and complexity. It is generally held that understanding land use and land cover change is essential to the public discourse on sustainability. It has been widely reported that the globe has been subject to a significant number of variations over the last decades [1-3]. These have frequently been correlated with the rise in deforestation, desertification, and land degradation observed in large parts of the area, and there has been a need for constant monitoring and oversight $[4,5]$.

However, despite its greatness to scientists and policy makers confronting the challenges of environmental change, land use and land cover change is still not well underpinned. Remote sensing offers cost-effective multispectral and multi-temporal information that is useful for the analysis and monitoring of land use models and trials and for the creation of land use and land cover data sets in a geographic information system context that provides a versatile environment for storing, analysing, and viewing digital information that is important for the identification of change and database evolution $[6,7]$.

Urban growth is actually a big category of land use and land use change, as it is related to a rise in populations and their financial systems [8]. More fundamentally, it has significant environmental consequences, such as the degradation of water and air quality [9]. It also has socioeconomic outcomes, including economic gaps, community disintegration, and improved infrastructure charges [10].

Remote sensing information has confirmed that it is important to observe and identify urban transformation, and to provide the necessary information for future progress. In the past, researchers and planners relied on visual aerial photo analysis to develop land exploitation plans [11]. Nevertheless, land use maps can now be made more appropriate, inexpensive, and more accurate with the growth of remote sensing devices and the availability of the latest highresolution digital technology [12]. Urbanised growth, driven by increasing population, economic development, and technological progress, has become an international phenomenon. Such development is often seen as the energy of a territorial economy [10, 13]. However, it has had unconstructive effects on the environment such as biodiversity deprivation, soil erosion, hydrological disturbances, water and solid contamination, and global warming. Monitoring and modelling urban spatial development are important for environmental sustainability and urban planning $[6,14]$.

The latest environmental and biological changes in the context of widespread and enhanced social inequality, along with the prevalence of poor living conditions, have had an effect on the pattern of disease spread. These environmental, economic, and political developments increase epidemiological uncertainty, favouring the introduction of new pathogens and the reemergence of old infectious diseases, historically linked to rural communities and potentially existing in new settings $[8,9]$. These concerns have prompted health-related organisations and, in addition, international institutions such as the World Health Organization to take action. A review of the scientific knowledge gained from the application of this approach to the study of endemic diseases, such as the coronavirus disease, is continuously carrying out. Analysis aims to evaluate the potential for the use of this technology as a tool for the study and management of the most prevalent and most dangerous diseases.

Recognition of changes is the method of identifying differences in land cover by monitoring them at various times [15]. Different methods of recognition of changes are usually compared to the most significant results of detection of changes for a specific function $[15$, 16]. The most commonly used methods of change detection are image differentiation, postclassification, transformation vector testing, and principal component analysis [17]. Studies confirm that these methods have been able to effectively recognise changes in diverse land 
cover through multi-temporal satellite images for different purposes $[18,19]$. Furthermore, the research looked at methods for the detection of functional change for urban change [14, 20].

\section{Satellite Imagery}

Satellite imagery refers to the assignment of globe imagery from detectors and sensors placed on sophisticated satellites in orbit around the globe [6,21]. Satellite images provide significant data that can be used in a number of remote sensing applications, such as meteorology, cartography, urban change recognition, and agricultural inspection. Campbell and Wynne [22] have identified and categorised the satellite images by four different types of image resolution:

1. Spatial resolution: The spatial resolution of a satellite picture refers to the dimension in square meter of the globe, calculated on the ground, which is covered by a picture pixel. Nevertheless, the most general metric used to illustrate spatial resolution is the metre, which explains the length of the ground on each side of the square image pixel [23]. The spatial resolution is influenced by the altitude of the satellite orbit around the globe, and also the type of sensors positioned on satellite. The higher the spatial resolution of the image is, the lower the surface area a pixel represents. As a result, a satellite image of elevated spatial resolution allows for a particular land vision given that even small objects are captured and then visible [24].

2. Spectral resolution: The spectral resolution of a satellite image is identified as the number of spectral bands it contains and the size of wavelength variation calculated in nanometres that each satellite image band captures [25]. This means that the spectral information extracted from each satellite may change. Most satellites can provide images with at least four channels where, apart from the standard red-green-blue (RGB) channels, there is also a near-infrared channel involved. For example, the IKONOS satellite provides 4-channel satellite images, while the LANDSAT-7 satellite gets 7-channel images. Moreover, even the wavelength interval of the same spectral channel may vary from sensing element to sensing element, and this means that the same spectral channel may contain slightly different information when captured from different sensing elements. Table 1 shows the wavelength and resolution for each specific band (http://web.pdx.edu/ nauna/resources/ 10_BandCombinations.htm). For example, the green channel of the QuickBird satellite consists of 520-600 nm, while the green channel of the WorldView-2 satellite consists of 510-580 nm. In addition, Table 2 shows the combination bands and corresponding frequencies (http://maps.unomaha.edu/Peterson/gis/notes/RS2.htm).

3. Temporal resolution: The temporal resolution of a satellite image refers to the time, normally counted in days, required by a satellite to perform a complete circle around the globe and return to the same position as before with the objective to accumulate picture of the identical surface zone [26]. This case of resolution depends mainly on the orbit of the satellite around the earth.

4. Radiometric resolution: The radiometric resolution of the satellite image refers to the degrees of brightness of the sensing elements that can be captured by the satellite. The radiometric resolution is described in bits and the most typical measurements are 8,11,12, and 16 bits. The range of values that the pixels of a satellite image can achieve depends on the radiometric resolution of the sensor used to capture the image [27]. In particular, given 
Table 1 Wavelength $(\mu \mathrm{m})$ and resolution $(\mathrm{m})$ bands of Landsat 7

\begin{tabular}{lll}
\hline Landsat 7 (ETM+ sensor) & Wavelength (micrometres) & Resolution (metres) \\
\hline Band 1 & $0.45-0.515$ & 30 \\
Band 2 & $0.525-0.605$ & 30 \\
Band 3 & $0.63-0.69$ & 30 \\
Band 4 & $0.75-0.90$ & 30 \\
Band 5 & $1.55-1.75$ & 30 \\
Band 6 & $10.40-12.5$ & 60 \\
Band 7 & $2.09-2.35$ & 30 \\
Pan band & $0.52-0.90$ & 15 \\
\hline
\end{tabular}

that the resolution of the radiometric image is $n$ bits, the intensity of the image pixels is within the range $(0,2 n-1)$. As a result, the pixel size of the 8-bit resolution image is within the range of $0-255$, while the pixel values of the 16-bit resolution image are within the range of $0-65535$ [28]. Figure 1 provides a global overview of the resolution types of the different optical satellite systems [29].

\section{Land Use Change Detection and Land Covering}

Land use and land cover change play a key role in global change and have important implications for many international policy developments. Over the last few decades, population growth and urbanisation have led to a dramatic transition from grassland and forest to cropland and residential areas. As a result, land use and land cover change have been a major concern for its results in terms of the water cycle, biological diversity, soils and their fertility, and water and air quality [30]. Careful consideration is shown by local and regional land managers and policy makers to take decisions that balance positive growth and bad with the

Table 2 Landsat TM band combinations

\begin{tabular}{|c|c|c|c|c|}
\hline Red & Green & Blue & Feature & Screen colour \\
\hline 7 & 4 & 2 & $\begin{array}{l}\text { Bare soil } \\
\text { Crops } \\
\text { Urban areas } \\
\text { Wetland vegetation } \\
\text { Trees }\end{array}$ & $\begin{array}{l}\text { Magenta/lavender/pink } \\
\text { Green } \\
\text { Lavender } \\
\text { Green } \\
\text { Green }\end{array}$ \\
\hline 3 & 2 & 1 & $\begin{array}{l}\text { Bare soil } \\
\text { Crops } \\
\text { Urban areas } \\
\text { Wetland vegetation } \\
\text { Trees }\end{array}$ & $\begin{array}{l}\text { White/light grey } \\
\text { Medium-light green } \\
\text { White/light grey } \\
\text { Dark green/black } \\
\text { Olive green }\end{array}$ \\
\hline 4 & 3 & 2 & $\begin{array}{l}\text { Bare soil } \\
\text { Crops } \\
\text { Urban areas } \\
\text { Wetland vegetation } \\
\text { Trees }\end{array}$ & $\begin{array}{l}\text { Blue/grey } \\
\text { Pink/red } \\
\text { Blue/grey } \\
\text { Dark red } \\
\text { Red }\end{array}$ \\
\hline 4 & 5 & 3 & $\begin{array}{l}\text { Bare soil } \\
\text { Crops } \\
\text { Urban areas } \\
\text { Wetland vegetation } \\
\text { Trees }\end{array}$ & $\begin{array}{l}\text { Green/dark blue } \\
\text { Yellow/tan } \\
\text { White/blue } \\
\text { Brown } \\
\text { Tan/orange brown }\end{array}$ \\
\hline
\end{tabular}



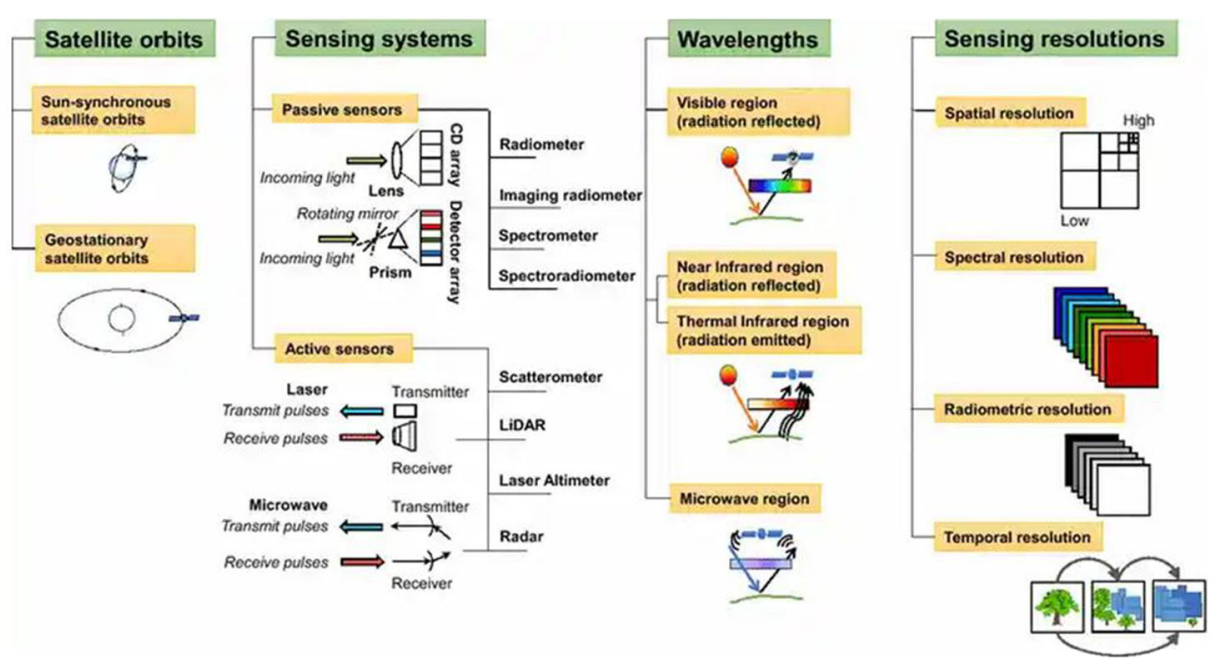

Fig. 1 An overview of spectral, spatial, temporal, and radiometric resolution of different optical satellite systems [26]

idea of maintaining environmental resources and enhancing socioeconomic well-being. In order to understand how land use and land cover change make and interact with global world schemes, it is necessary to provide information on what changes occur, when and where they seem, the values at which they occur, and the natural and social drivers of these changes [31].

Satellite remote sensing data may provide useful information on the geographical dispersion of land use and land cover change, along with price and time savings for information gathering over traditional inventories and studies across large regions [32]. In addition, data on remote sensing may provide information on the temporal trends and spatial distributions of urbanised regions involved in understanding, modelling, and designing land change. Figure 2 shows the main devices used for remote sensing imaging [33]. Remote sensing change detection is the process of identifying differences in the status of an object or phenomenon by observing it at different times. Remotely sensed data has become a major source of

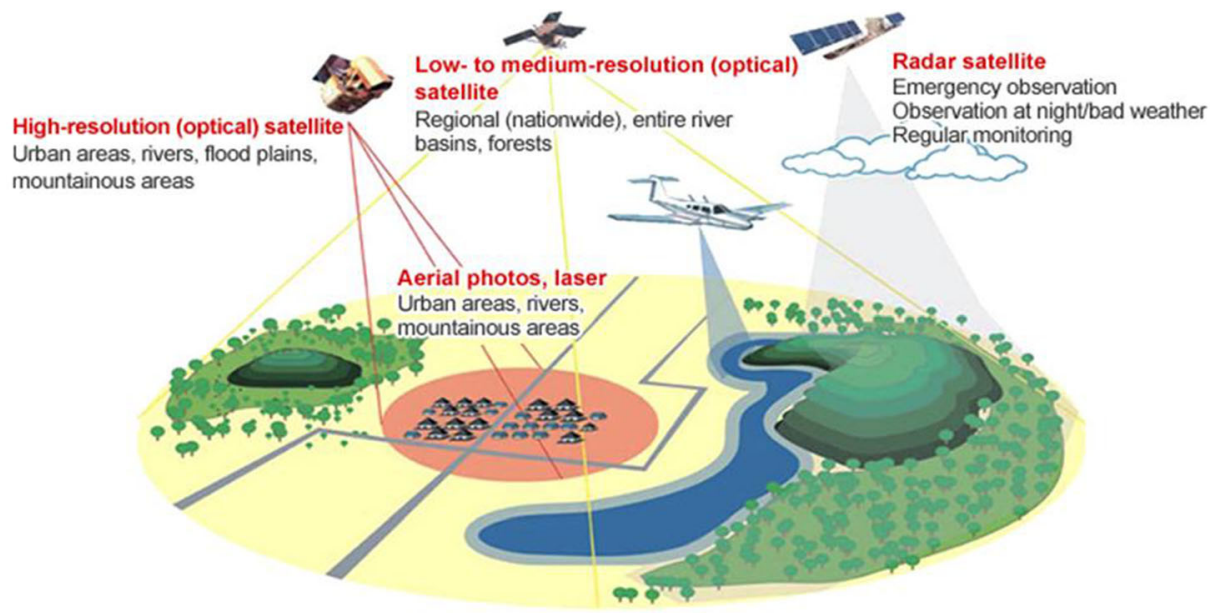

Fig. 2 The main devices used for remote sensing imagery [33] 
information for various change detection application programmes in recent decades, due to repetitive data acquisition and digital formats that are suitable for computer processing [34]. Although most of the change detecting research studies have focused on land use and land cover change, recent work has used change detection techniques in a number of applications, such as forestry [35] and vegetation modification, forest fire [36], wetland change, and urban change [37].

\section{Urban Change Detection}

Land cover change and land use are key elements of global environmental change and have significant impacts on many aspects of ecosystem processes and functions at local, regional, and global scales. Over the last few decades, agricultural expansion and intensification, deforestation, and urbanisation have progressively affected more than half of the Earth's unfrozen surface [38]. A number of published studies have suggested that land cover change and land use have significant impacts on biodiversity, water production and quality, climate, soil status, food protection, and human well-being [39-41]. Although urbanised regions comprise only a small part of the world's land area, urbanisation is widely viewed as the most intensive and important land cover change and land use type [42]. Land transformations from forest and other natural land to urbanised land are typically permanent and may lead to a number of ecosystem-related problems, such as impaired air and water quality, the spread of invasive species, and habitat fragmentation [43]. With the rapid migration of population to urban areas, urbanisation processes have accelerated over the last decades. Monitoring past and recent urban scale and urbanisation operations is of vital importance for the assessment of ecosystem services and for the promotion of policy making [44].

Urbanisation is one of the most important forms of global change in both developing and developed countries. Urbanisation is caused by the growth of population and economy, as well as by the concentration of human population in large metropolitan areas. Inappropriate land preparation and land management cover changes associated may be associated to. The urban development may have major impacts on climate and ecosystems, including degradation of water and air quality, loss of farmland and forests, and the socioeconomic effects of economic disparities, social fragmentation, and monetary value of infrastructure [45]. In addition, urban areas have higher solar radiation absorption and thermal capacity and conductivity than other land-based types. As a result, urban areas tend to have higher temperatures than adjacent agricultural areas due to impervious surfaces such as roads and buildings. This thermal difference leads to the development of urban thermal islands [46]. Monitoring and representing the urban development needs robust techniques and methods. Traditional study and mapping methods do not have the capacity to provide the necessary data in a timely and cost-effective manner. In recent decades, studies have shown the potential for remote sensing modification detection techniques to provide accurate and timely data on urbanised land change [47, 48]. Mas [49] found that post-classification is the most successful method of urban change detection, with information on various soil moisture and vegetation phenology circumstances. In addition, Li and Yeh [50] concluded that multi-date principal component analysis (PCA) and categorization could be successfully applied to determine rapid urbanised expansion in the Chinese river. Principal component analysis is the foundation of a multivariate analysis of data based on projection techniques. The most significant application of principal component analysis is the implementation of a multivariate record board as a small set of variables with 
the aim of viewing trends, bounds, groups, and outliers [51]. Principal component analysis is a very flexible device and allows the study of datasets that may include, for example, multicollinearity, misplaced values, and categorical records, in addition to incorrect data [52]. The objective is to detect and express significant data records as a set of primary indices or main components [51, 53]. Anees et al. [54] used remote sensing with geographic information systems (GIS) change detection techniques to map the spatial dynamics of urban land modifications.

The main challenge for the categorization of urbanised land cover is to accurately identify the relative contribution of reflection from a number of materials in an urbanised environment. Furthermore, consideration needs to be given for changes that are not linked to urbanised land cover change, such as seasonal vegetation variations. In addition, some works, including other spatial data, have been investigated in order to overcome the sub-pixel mixing problem and improve per-pixel compartmentalisation by using textural [55] and contextual [56] information.

\section{Change Detection}

Detection of changes in computer vision can generally be identified as a problem with the identification of the character and magnitude of the changes between the two compared images that describe the corresponding scene and were obtained at different time periods. Depending on the objectives of each task, some changes are fundamental and require further analysis and modelling, while others are superficial or improper and should be discarded. Detection of change can be a challenging task as it affects various elements, such as temporal, spectral and spatial, restraint, radiometric resolution, and atmospheric conditions [57]. In an effort to overcome the difficulties and provide accurate change in the detection of outcomes, different changes to detecting skills have been prepared. Authors grouped change detection techniques based on different points of view and grouped them into pre-classification or postclassification methods [58] and pixel-based or object-based methods [59]. Pixel-based change detection methods consider the image pixel to be the basic unit of image analysis and change. These techniques, which can also be considered as pre-classification techniques due to the fact that they are employed on raw data, are most often used in the literature on change detection methods. Several pixel-based change detection methods have been developed and their advantages and disadvantages have been analysed in an attempt to improve the accuracy of the change detection $[60,61]$.

Famous pixel-based change detection techniques include image differentiation, image rationing, picture regression, background subtraction, principal component analysis, and change vector analysis (CVA). Change vector analysis is used to recognise spectral changes involving two identical scenes that have been produced at different times. Change vector analysis is limited to two bands for each image. The change vector in the spectral dualdimensional space is estimated for each pixel. It explains the transformation of one attribute across a variety of events (variables) between two limits of time as a vector within the space of variables [62]. Fundamentally, a vector with a direction element and a magnitude can be expressed. The magnitude constituent expresses the quantity of change as the direction element indicates the type of change. Picture differentiation calculates the absolute differences between the pixel values of the grayscale image and is the easiest way to execute, but no information on the type of change is provided. An overview of the use of image differentiation 
for land cover change detection was provided in [63]. Image rationing calculates the ratio of grayscale pixel measurements and it has the reward that it is better able to handle calibration errors [64] but no complete change data matrix is provided. Picture regression attempts to adjust the pixel values of the objective image to those of the reference image by regression analysis. It accounts for variations in mean and variance between pixel measurements for different dates and thus reduces the adverse effects caused by atmospheric conditions and sun angles [65]. Unfortunately, it is difficult to determine precise regression functions due to local luminance fluctuations present in images. Background subtraction [66] attempts to find the background information from the photos compared and then deducts it from the photos in order to obtain change information. Although simple to implement, the background subtraction is subject to low accuracy [67].

Principal component analysis applies dimensionality reduction to the withdrawal of information redundancy between multispectral bands and the punctuation of different information. Principal component analysis was used in [68] as a distance metric to determine the magnitude of change in the value of the pixel when the Bayes principle was used to distinguish pixels in two classes, "change" and "no change". The disadvantages of the principal component analysis change detection methods are the difficulty in interpreting and labelling the results of the principal component analysis and the lack of extracted data on the nature of the changes [69].

In contrast to previous pixel-based change detection techniques, the change vector analysis can provide information on the type of change. Change vector analysis uses all the available multispectral image data, interprets each pixel as a vector, and differentiates on vectors. As a result, the Euclidean vector distance identifies the magnitude of the change, while the vector angle provides information on the type of change. The disadvantage of changing vector analysis change detection method is that it requires accurate radiometric correction for atmospheric effects to be mitigated and such precise radiometric correction is not possible [19]. All pixel-based change detection methods suffer from two major disadvantages or limitations that have led to research into object-based change detection techniques. The first drawback is that a threshold is necessary to distinguish between pixels that belonging to the "change" class from those that belonging to the "no change" class. Selecting the optimum threshold is a problematic procedure and pixel-based techniques are usually subject to misdetection or over-detection [70]. This is because the threshold is too weak to allow too many surfaces of change, while the threshold is too high to expel surfaces of change. The other limitation of pixel-based techniques is the fact that they do not take into account the spatial links between adjacent pixels [71]. This exclusion from the spatial context leads to the removal of primary information, which would greatly contribute to accurate results in the detection of changes. The special subcategory of pixel-based change detection techniques is based on texture analysis methods. These methods are used at the window/block level, implying that the statistical characteristics are calculated over the imbrications windows that move across the compared images. As a result, these techniques take into account the spatial setting of pixels and they may be more noise-proof than other pixel-based techniques.

Change detection solutions for these algorithms are based on the rating of similarity metrics between the windows being compared. A common similarity metric used in several texture analysis supported change detection methodologies is a correlation that can be used either in the time domain in the form of normalised cross-correlation (NCC) [72] or in the frequency domain by transforming images using Fourier and then analysing the index spectrum (phase correlation (PC)) [73]. NCC is a main mathematical instrument for signal and image 
processing for character matching, correspondence analysis, signal tracking, and object identification $[74,75]$. In order to improve its real-time and efficient performance, it was suggested that digital standardised cross-correlation be implemented by some fast algorithms and hardware structures due to its high computational complexity [76, 77].

In addition, the Bhattacharyya distance is used to compare pixels inside the imbrication windows [78]. In digital image processing, an estimate of the theoretical distance involves two normal distributions of spectral categories, which operates as a higher boundary on the possibility of miscalculation in a Bayesian approximation of the acceptable classification.

Texture-based methods are subject to the same limitation as different pixel-based techniques, which is the demand for the best threshold that distinguishes pixels that correspond to true changes from all other pixels. In an attempt to overcome the limitations of pixel-based change detection techniques, object-based methods have been developed. Object-based methods can usually be identified as post-classification methods due to the fact that the images are commonly fragmented into regions or categories before any change detection method is used. The unit for analysis in object-based change detection techniques is an image object with valuable data, such as texture, shape, and spatial relations with adjacent objects, providing for the use of spatial settings [79].

Picture partition is at the centre of the object-based change detection methods and different supervised or unsupervised partition techniques are used with varying results. Most objectbased change detection techniques can be classified in either field-based (similarity of pixels) or boundary-based (discontinuity of pixels) or edge-based methods [80]. The expectationmaximization (EM) algorithms [81], the artificial neural networks (ANNs) [82], and the support vector machine (SVM) classifiers [7, 83] are image partition algorithms that are usually used in object-based change detecting methodological analyses. The expectationmaximization algorithm is a methodology for achieving the maximum probability assessment of hidden variables. It does this by first approximating the values for hidden variables, then optimising the prototype, and then reiterating the two steps of the union. It is an efficient and common methodology and is most commonly used for density evaluation through missing records, such as clustering algorithms such as the Gaussian mixture model.

In addition, support vector machines are a kind of machine learning classifier, possibly one of the most common types of classifiers. Support vector machines are particularly useful for numerical prediction, categorization, and sample detection tasks [12, 21]. Support vector machines run through the representation of decision limits between records points, aiming at a decision boundary that most excellently divides the information points into categories. The objective when using a support vector machine is that the decision boundary between the points is as large as possible so that the distance between the specified data point and the boundary contour is maximized.

Change detection methods based on the EM algorithm achieve higher accuracy than other methods but they require a priori knowledge of the joint probability class [81]. The artificial neural networks approach can provide significant change detection results, particularly when categories are not normally distributed, but it needs a lot of preparation time and it is sensitive to the amount of training data [84]. Artificial neural networks are seen as nonlinear statistical data modelling tools where complex relationships involving inputs and outputs are designed or patterns are found. Data flowing through the network affects the structure of artificial neural networks because the neural network varies on the basis of input and output. Artificial neural networks are deep learning frameworks capable of forming identification and machine learning. They are part of the broader domain of artificial intelligence (AI) technology [85]. 
Finally, the advantage of support vector machine classifiers is that they do not make assumptions about the underlying data distribution and process the task of detecting change as a dual classification problem. The support vector machine classifier learns from the training records and the optimum threshold is automatically defined [86] from the spectral characteristics with the aim of classifying the pixels in the "no change" or "change" categories. Other machine learning algorithms used to monitor categorization, classification, and change detection include fuzzy logic [87], random forest [88], or genetic programming [89]. Fuzzy logic is a valued logic structure that may have accurate variable values in any actual number between 0 and 1. The fuzzy logic algorithm makes it easier to resolve a problem after taking into account all existing records. After that, the most likely result for the specified input is taken. Common phenomena, such as environmental change, rarely have crisp limits and therefore cannot be approached in the conventional method by means of dual logic (weak or not: 0 or 1) [90]. As a result of fuzzy logic, units are allowed to have a partial association with a given category, which is allocated through bias formulas. Among the fuzzy relational calculus, a numerical foundation is built to treat all types of cases where the uncertainty of the status of the environment cannot be ignored.

Lately, random forest algorithm has become particularly famous in the field of remote sensing, and is rather quick compared to other machine learning methodologies [91]. The concise description of the random forest algorithm is derived from the denomination. Rather than employing the forecast of an individual decision tree, the algorithm will result in a large number of decision trees being assembled. The "random" fraction of the name comes from the expression "bootstrap aggregating", or "bagging". This means that every tree within the forest can only learn to train on some division of the complete training dataset. The components of the training records for each tree left hidden are believed to be "out-of-bag" for precision evaluation. Uncertainty also helps to having the choice which variables of the input attribute are observed at each node in each decision tree. Once all the trees are robust for random division of the training records, by means of an arbitrary set of attribute variables for each node, the assembly of all the trees is used to provide the final forecast [92].

Genetic algorithms (GA) are the ideal option for heuristic unsupervised classification. Heuristic unsupervised classification is based on the creation of some mathematical designs and, subsequently, the improvement of a predefined indicator to determine the cluster information and the centroids mechanically [93]. Heuristic optimization procedures are considered to be a reproducible, accurate, and time-efficient method of repeatedly categorising remote sensing images. Previously, genetic algorithms have been successfully approved for image processing [94] and image identification for specific uses such as therapeutic treatment [95].

Object-based techniques that rely on image segmentation suffer from oversegmentation or under-segmentation miscalculations. Such miscalculations produce objects that do not accurately represent real-world objects [96]. Under-segmentation creates larger objects that hide more than one object in the real world, and they may contain mixed categories of objects, whereas over-segmentation creates finer components of reallife objects that need to be merged to make current objects more pragmatic [97]. Unfortunately, the miscalculations of the used image classification process are disseminated in the final change map, which reduces the accuracy of the most recent change detection results [98]. In order to improve the results of the change detection, the classification of individual images must be as accurate as possible. 


\section{Conclusion}

Apparent urban growth, driven by rising population, economic expansion, and technological progress, has become an international trend. Such growth is often seen as the strength of a local economy. However, it has had unconstructive effects on the environment, such as biodiversity loss, soil erosion, hydrological disturbances, water and solid contamination, and global warming. Screening and modelling of urban spatial expansion are essential for ecological sustainability and urban planning. Due to the ability to deal with nonlinear and multifaceted phenomena, the integration of analytical techniques and methods with remote sensing has enhanced the performance of image classification for the disjointed and varied landscape in the urban environment. The other component is to differentiate spatial urban expansion in the practical zone, and cellular phases by using three methodologies: urban land change planning, site metrics survey, and moving windows examination.

Author Contribution KE wrote the paper. SS and MAT advised the first author and improved the manuscript.

Data Availability N/A.

\section{Declarations}

Conflict of Interest The authors declare no competing interests.

\section{References}

1. Guo HD, Zhang L, Zhu LW (2015) Earth observation big data for climate change research. Adv Clim Chang Res 6(2):108-117

2. Arnell NW, Brown S, Gosling SN, Gottschalk P, Hinkel J, Huntingford C, Lloyd-Hughes B, Lowe JA, Nicholls RJ, Osborn TJ, Osborne TM, Rose GA, Smith P, Wheeler TR, Zelazowski P (2016) The impacts of climate change across the globe: a multi-sectoral assessment. Clim Change 134(3):457-474

3. Munang R, Thiaw I, Alverson K, Mumba M, Liu J, Rivington M (2013) Climate change and ecosystembased adaptation: a new pragmatic approach to buffering climate change impacts. Curr Opin Environ Sustain 5(1):67-71

4. Borrelli P, Robinson DA, Fleischer LR, Lugato E, Ballabio C, Alewell C et al (2017) An assessment of the global impact of 21 st century land use change on soil erosion. Nat Commun 8(1):1-13

5. D'Odorico P, Bhattachan A, Davis KF, Ravi S, Runyan CW (2013) Global desertification: drivers and feedbacks. Adv Water Resour 51:326-344

6. Ennouri K, Triki MA, Kallel A (2020) Applications of remote sensing in pest monitoring and crop management. In: Keswani C (ed) Bioeconomy for sustainable development. Springer, Singapore. https:// doi.org/10.1007/978-981-13-9431-7 5

7. Ennouri K, Ottaviani E, Smaoui S, Triki MA (2020) Use of remote sensing technology and geographic information system for agriculture and environmental observation in Ennouri, K. (Ed.). Emerging technologies in agriculture and food science. Bentham Science Publishers. Pp. 108-138 (31) DOI:https://doi.org/10. 2174/97898114700041200101

8. Patino JE, Duque JC (2013) A review of regional science applications of satellite remote sensing in urban settings. Comput Environ Urban 37:1-17

9. McCarty J, Kaza N (2015) Urban form and air quality in the United States. Landsc Urban Plan 139:168-179

10. Keola S, Andersson M, Hall O (2015) Monitoring economic development from space: using nighttime light and land cover data to measure economic growth. World Dev 66:322-334

11. Barrientos A, Colorado J, Cerro JD, Martinez A, Rossi C, Sanz D, Valente J (2011) Aerial remote sensing in agriculture: a practical approach to area coverage and path planning for fleets of mini aerial robots. J Field Robot 28(5):667-689 
12. Ottaviani E, Barelli E, Ennouri K (2020) Machine learning for precision agriculture: methods and applications. In: Ennouri K (ed) Emerging technologies in agriculture and food science. Bentham Science Publishers, pp 91-107. https://doi.org/10.2174/97898114700041200101

13. Hegazy IR, Kaloop MR (2015) Monitoring urban growth and land use change detection with GIS and remote sensing techniques in Daqahlia governorate Egypt. Int J Sustain Built Environ 4(1):117-124

14. Weng Q (2012) Remote sensing of impervious surfaces in the urban areas: requirements, methods, and trends. Remote Sens Environ 117:34 49

15. Kuenzer C, Bluemel A, Gebhardt S, Quoc TV, Dech S (2011) Remote sensing of mangrove ecosystems: a review. Remote Sens 3(5):878-928

16. Rawat JS, Kumar M (2015) Monitoring land use/cover change using remote sensing and GIS techniques: a case study of Hawalbagh block, district Almora, Uttarakhand, India. Egyptian J Remote Sens Space Sci 18(1):77-84

17. Peiman R (2011) Pre-classification and post-classification change-detection techniques to monitor landcover and land-use change using multi-temporal Landsat imagery: a case study on Pisa Province in Italy. Int J Remote Sens 32(15):4365-4381

18. Xu M, Cao C, Zhang H, Guo J, Nakane K, He Q, Guo J, Chang C, Bao Y, Gao M, Li X (2010) Change detection of an earthquake-induced barrier lake based on remote sensing image classification. Int J Remote Sens 31(13):3521-3534

19. Tewkesbury AP, Comber AJ, Tate NJ, Lamb A, Fisher PF (2015) A critical synthesis of remotely sensed optical image change detection techniques. Remote Sens Environ 160:1-14

20. Hu S, Wang L (2013) Automated urban land-use classification with remote sensing. Int J Remote Sens 34(3):790-803

21. Ennouri K, Kallel A (2019) Remote sensing: an advanced technique for crop condition assessment. Math Probl Eng 2019

22. Campbell JB, Wynne RH (2011) Introduction to remote sensing. Guilford Press

23. Han X, Zhong Y, Cao L, Zhang L (2017) Pre-trained alexnet architecture with pyramid pooling and supervision for high spatial resolution remote sensing image scene classification. Remote Sens 9(8):848

24. Li W, Fu H, Yu L, Cracknell A (2017) Deep learning based oil palm tree detection and counting for highresolution remote sensing images. Remote Sens 9(1):22

25. Zhao B, Zhong Y, Zhang L (2016) A spectral-structural bag-of-features scene classifier for very high spatial resolution remote sensing imagery. ISPRS J Photogramm Remote Sens 116:73-85

26. Battude M, Al Bitar A, Morin D, Cros J, Huc M, Sicre CM et al (2016) Estimating maize biomass and yield over large areas using high spatial and temporal resolution Sentinel-2 like remote sensing data. Remote Sens Environ 184:668-681

27. Verde N, Mallinis G, Tsakiri-Strati M, Georgiadis C, Patias P (2018) Assessment of radiometric resolution impact on remote sensing data classification accuracy. Remote Sens 10(8):1267

28. Kwan C (2018) Image resolution enhancement for remote sensing applications. In: Proceedings of the 2 nd International Conference on Vision, Image and Signal Processing, pp 1-5

29. Kadhim N, Mourshed M, Bray M (2016) Advances in remote sensing applications for urban sustainability. Euro-Mediterr J Environ Integr 1:7. https://doi.org/10.1007/s41207-016-0007-4

30. Zope PE, Eldho TI, Jothiprakash V (2016) Impacts of land use-land cover change and urbanization on flooding: a case study of Oshiwara River Basin in Mumbai, India. Catena 145:142-154

31. Findell KL, Berg A, Gentine P, Krasting JP, Lintner BR, Malyshev S et al (2017) The impact of anthropogenic land use and land cover change on regional climate extremes. Nat commun 8(1):1-10

32. Camilleri S, De Giglio M, Stecchi F, Pérez-Hurtado A (2017) Land use and land cover change analysis in predominantly man-made coastal wetlands: towards a methodological framework. Wetl Ecol Manag 25(1): 23-43

33. Services for conservation of forest and environmental resources. https://www.kkc.co.jp/english/service/env energy/k_green_solar.html

34. Weiss M, Jacob F, Duveiller G (2020) Remote sensing for agricultural applications: a meta-review. Remote Sens Environ 236:111402

35. Torresan C, Berton A, Carotenuto F, Di Gennaro SF, Gioli B, Matese A et al (2017) Forestry applications of UAVs in Europe: a review. Int J Remote Sens 38(8-10):2427-2447

36. Youn H, Jeong J (2019) Detection of forest fire and NBR mis-classified pixel using multi-temporal Sentinel2A images. Korean J Remote Sens 35:1107-1115

37. Ballanti L, Byrd KB, Woo I, Ellings C (2017) Remote sensing for wetland mapping and historical change detection at the Nisqually River Delta. Sustainability 9(11):1919

38. Lynch J, Maslin M, Balzter H, Sweeting M (2013) Choose satellites to monitor deforestation. Nature 496: 293-294 
39. Sterling SM, Ducharne A, Polcher J (2013) The impact of global land-cover change on the terrestrial water cycle. Nat Clim Change 3(4):385-390

40. Kayet N, Pathak K, Chakrabarty A, Sahoo S (2016) Spatial impact of land use/land cover change on surface temperature distribution in Saranda Forest, Jharkhand. Model Earth Syst Environ 2(3):127

41. Zhang Y, Liang S (2018) Impacts of land cover transitions on surface temperature in China based on satellite observations. Environ Res Lett 13(2):024010

42. Petrișor AI, Ianoș I, Tălângă C (2010) Land cover and use changes focused on the urbanization processes in Romania. Environ Eng Manag J (EEMJ) 9(6)

43. Cui L, Shi J (2012) Urbanization and its environmental effects in Shanghai, China. Urban Clim 2:1-15

44. Wu Y, Zhang X, Shen L (2011) The impact of urbanization policy on land use change: a scenario analysis. Cities 28(2):147-159

45. Yin J, Yin Z, Zhong H, Xu S, Hu X, Wang J, Wu J (2011) Monitoring urban expansion and land use/land cover changes of Shanghai metropolitan area during the transitional economy (1979-2009) in China. Environ Monit Assess 177:609-621

46. Kuang W, Liu A, Dou Y, Li G, Lu D (2019) Examining the impacts of urbanization on surface radiation using Landsat imagery. GISci Remote Sens 56(3):462-484

47. Melchiorri M, Florczyk AJ, Freire S, Schiavina M, Pesaresi M, Kemper T (2018) Unveiling 25 years of planetary urbanization with remote sensing: perspectives from the global human settlement layer. Remote Sens 10(5):768

48. Akbar TA, Hassan QK, Ishaq S, Batool M, Butt HJ, Jabbar H (2019) Investigative spatial distribution and modelling of existing and future urban land changes and its impact on urbanization and economy. Remote Sens 11(2):105

49. Mas JF (1999) Monitoring land-cover changes: a comparison of change detection techniques. Int J Remote Sens 20(1):139-152

50. Li X, Yeh AGO (1998) Principal component analysis of stacked multi-temporal images for the monitoring of rapid urban expansion in the Pearl River Delta. Int J Remote Sens 19(8):1501-1518

51. Ennouri K, Ben Ayed R, Ben Hlima H et al (2020) Analysis of variability in Pistacia vera L. fruit genotypes based on morphological attributes and biometric techniques. Acta Physiol Plant 42:70. https://doi.org/10. 1007/s11738-020-03058-4

52. Yang JH, Zhao XL, Ji TY, Ma TH, Huang TZ (2020) Low-rank tensor train for tensor robust principal component analysis. Appl Math Comput 367:124783

53. Ennouri K, Ayed RB, Smaoui S (2018) Opportunities for computational biology uses in enhancement of bioproduct quality: lessons from olive oil. Emir J Food Agr:532-538

54. Anees MM, Mann D, Sharma M, Banzhaf E, Joshi PK (2020) Assessment of urban dynamics to understand spatiotemporal differentiation at various scales using remote sensing and geospatial tools. Remote Sens 12(8): 1306

55. Mishra VN, Prasad R, Rai PK, Vishwakarma AK, Arora A (2019) Performance evaluation of textural features in improving land use/land cover classification accuracy of heterogeneous landscape using multisensor remote sensing data. Earth Sci Inform 12(1):71-86

56. Sun Y, Xin Q, Huang J, Huang B, Zhang H (2019) Characterizing tree species of a tropical wetland in southern china at the individual tree level based on convolutional neural network. IEEE J Sel Top Appl Earth Obs Remote Sens 12(11):4415-4425

57. Asokan A, Anitha J (2019) Change detection techniques for remote sensing applications: a survey. Earth Sci Inform 12(2):143-160

58. Wu C, Du B, Cui X, Zhang L (2017) A post-classification change detection method based on iterative slow feature analysis and Bayesian soft fusion. Remote Sens Environ 199:241-255

59. Xiao P, Zhang X, Wang D, Yuan M, Feng X, Kelly M (2016) Change detection of built-up land: a framework of combining pixel-based detection and object-based recognition. ISPRS J Photogramm Remote Sens 119:402-414

60. Hecheltjen A, Thonfeld F, Menz G (2014) Recent advances in remote sensing change detection-a review. In: Land Use and Land Cover Mapping in Europe. Springer, Dordrecht, pp 145-178

61. Hussain M, Chen D, Cheng A, Wei H, Stanley D (2013) Change detection from remotely sensed images: from pixel-based to object-based approaches. ISPRS J Photogramm Remote Sens 80:91-106

62. Landmann T, Schramm M, Huettich C, Dech S (2013) MODIS-based change vector analysis for assessing wetland dynamics in Southern Africa. Remote Sens Lett 4(2):104-113

63. Abd El-Kawy OR, Rød JK, Ismail HA, Suliman AS (2011) Land use and land cover change detection in the western Nile delta of Egypt using remote sensing data. Appl Geogr 31(2):483-494

64. Chen B, Huang B, Xu B (2017) Multi-source remotely sensed data fusion for improving land cover classification. ISPRS J Photogramm Remote Sens 124:27-39 
65. Senf C, Laštovička J, Okujeni A, Heurich M, van der Linden S (2020) A generalized regression-based unmixing model for mapping forest cover fractions throughout three decades of Landsat data. Remote Sens Environ 240:111691

66. Shen W, Lin Y, Yu L, Xue F, Hong W (2018) Single channel circular SAR moving target detection based on logarithm background subtraction algorithm. Remote Sens 10(5):742

67. Shah M, Cave V, Dos Reis M (2020) Automatically localising ROIs in hyperspectral images using background subtraction techniques. In 2020 35th International Conference on Image and Vision Computing New Zealand (IVCNZ) (pp. 1-6). IEEE.

68. Almutairi A, Warner TA (2010) Change detection accuracy and image properties: a study using simulated data. Remote Sens 2(6):1508-1529

69. Sahu DK, Parsai MP (2012) Different image fusion techniques-a critical review. International Journal of Modern Engineering Research (IJMER) 2(5):4298-4301

70. Konstantinidis D (2017) Building detection for monitoring of urban changes.

71. Sharma A, Liu X, Yang X, Shi D (2017) A patch-based convolutional neural network for remote sensing image classification. Neural Networks 95:19-28

72. Debella-Gilo M, Kääb A (2011) Sub-pixel precision image matching for measuring surface displacements on mass movements using normalized cross-correlation. Remote Sens Environ 115(1):130-142

73. Sarvaiya JN, Patnaik S, Kothari K (2012) Image registration using log polar transform and phase correlation to recover higher scale. J Pattern Recognit Res 7(1):90-105

74. Jawak SD, Kumar S, Luis AJ, Bartanwala M, Tummala S, Pandey AC (2018) Evaluation of geospatial tools for generating accurate glacier velocity maps from optical remote sensing data. In: Multidisciplinary Digital Publishing Institute Proceedings, vol 2, No. 7, p 341

75. Cai J, Wang C, Mao X, Wang Q (2017) An adaptive offset tracking method with SAR images for landslide displacement monitoring. Remote Sens 9(8):830

76. Ma J, Zhou H, Zhao J, Gao Y, Jiang J, Tian J (2015) Robust feature matching for remote sensing image registration via locally linear transforming. IEEE Trans Geosci Remote Sens 53(12):6469-6481

77. Wickramasinghe DC, Vu TT, Maul T (2018) Satellite remote-sensing monitoring of a railway construction project. Int J Remote Sens 39(6):1754-1769

78. Xun L, Wang L (2015) An object-based SVM method incorporating optimal segmentation scale estimation using Bhattacharyya Distance for mapping salt cedar (Tamarisk spp.) with QuickBird imagery. GIS Remote Sens 52(3):257-273

79. Ma L, Li M, Blaschke T, Ma X, Tiede D, Cheng L, Chen Z, Chen D (2016) Object-based change detection in urban areas: the effects of segmentation strategy, scale, and feature space on unsupervised methods. Remote Sens 8(9):761

80. Aptoula E (2013) Remote sensing image retrieval with global morphological texture descriptors. IEEE Trans Geosci Remote Sens 52(5):3023-3034

81. Lv Z, Liu T, Atli Benediktsson J, Lei T, Wan Y (2018) Multi-scale object histogram distance for LCCD using bi-temporal very-high-resolution remote sensing images. Remote Sens 10(11):1809

82. Şahin M (2012) Modelling of air temperature using remote sensing and artificial neural network in Turkey. Adv Space Res 50(7):973-985

83. Yu L, Porwal A, Holden EJ, Dentith MC (2012) Towards automatic lithological classification from remote sensing data using support vector machines. Comput and Geosci 45:229-239

84. Ennouri K, Ben Hlima H, Ben Ayed R, Ben Braïek O, Mazzarello M, Ottaviani E, Mallouli L, Smaoui S (2019) Assessment of Tunisian virgin olive oils via synchronized analysis of sterols, phenolic acids, and fatty acids in combination with multivariate chemometrics. Eur Food Res Technol 245:1811-1824. https:// doi.org/10.1007/s00217-019-03303-2

85. Ennouri K, Ayed RB, Triki MA, Ottaviani E, Mazzarello M, Hertelli F, Zouari N (2017) Multiple linear regression and artificial neural networks for delta-endotoxin and protease yields modelling of Bacillus thuringiensis. 3 Biotech 7(3):187

86. Thanh Noi P, Kappas M (2018) Comparison of random forest, k-nearest neighbor, and support vector machine classifiers for land cover classification using Sentinel-2 imagery. Sensors 18(1):18

87. Pradhan B (2010) Application of an advanced fuzzy logic model for landslide susceptibility analysis. Int J Comput Intell Syst 3(3):370-381

88. Belgiu M, Drăguț L (2016) Random forest in remote sensing: a review of applications and future directions. ISPRS J Photogramm Remote Sens 114:24-31

89. Li S, Wu H, Wan D, Zhu J (2011) An effective feature selection method for hyperspectral image classification based on genetic algorithm and support vector machine. Knowl Based Syst 24(1):40-48

90. Bouamrane A, Derdous O, Dahri N, Tachi SE, Boutebba K, Bouziane MT (2020) A comparison of the analytical hierarchy process and the fuzzy logic approach for flood susceptibility mapping in a semi-arid ungauged basin (Biskra basin: Algeria). Int J River Basin Manag:1-11 
91. Izquierdo-Verdiguier E, Zurita-Milla R (2020) An evaluation of guided regularized random forest for classification and regression tasks in remote sensing. Int J Appl Earth Obs Geoinf 88:102051

92. Chen Q, Miao F, Wang H, Xu ZX, Tang Z, Yang L, Qi S (2020) Downscaling of satellite remote sensing soil moisture products over the Tibetan Plateau based on the random forest algorithm: preliminary results. Earth Space Sci 7(6):e2020EA001265

93. Al-Fugara AK, Ahmadlou M, Al-Shabeeb AR, AlAyyash S, Al-Amoush H, Al-Adamat R (2020) Spatial mapping of groundwater springs potentiality using grid search-based and genetic algorithm-based support vector regression. Geocarto Int: $1-20$

94. Celik T (2010) Change detection in satellite images using a genetic algorithm approach. IEEE Geosci Remote Sens Lett 7(2):386-390

95. Reddy GT, Reddy MPK, Lakshmanna K, Rajput DS, Kaluri R, Srivastava G (2020) Hybrid genetic algorithm and a fuzzy logic classifier for heart disease diagnosis. Evol Intell 13(2):185-196

96. Grigillo D, Kanjir U (2012) Urban object extraction from digital surface model and digital aerial images. ISPRS Annals of the Photogrammetry, Remote Sensing and Spatial Information Sciences 3: 215-220.

97. Wang Z, Jensen JR, Im J (2010) An automatic region-based image segmentation algorithm for remote sensing applications. Environ Model Softw 25(10):1149-1165

98. Si A, Zhang J, Tong S, Lai Q, Wang R, Li N, Bao Y (2018) Regional landslide identification based on susceptibility analysis and change detection. ISPRS Int J Geo-Inf 7(10):394 